\title{
Intervenções urbanas em áreas deterioradas
}

\section{Urban interventions in deteriorated areas}

\author{
Denise de Cássia Rossetto Januzzi ${ }^{1}$; Nestor Razente ${ }^{2}$
}

\section{Resumo}

As transformações econômicas e sociais ocorridas no Século XX fizeram surgir em muitas cidades espaços ociosos ou deteriorados, o que exigiu a adoção de procedimentos de intervenção urbana. Com a devida fundamentação teórica, este trabalho procura identificar os principais tipos de intervenções urbanas adotados nas últimas décadas, em especial aqueles voltados para a revitalização de espaços decadentes. Esta é uma contribuição para o estudo do Urbanismo e a aplicação dos métodos e técnicas de Desenho Urbano.

Palavras-chave: Áreas centrais. Revitalização. Áreas deterioradas.

\begin{abstract}
The economical and social transformations that occurred in the $20^{\text {th }}$ century created inactive and deteriorated spaces in many cities, which demanded the adoption of some urban intervention procedures. With the right theoretical foundation, this paper tries to identify the main types of urban interventions adopted in the last decades, especially those designed to revitalize decadent spaces. This is a contribution to Urbanism studies and to the application of Urban Design methods and techniques.
\end{abstract}

Key words: Central areas. Revitalization. Deteriorated areas.

\section{Introdução}

Este artigo investiga um tipo específico de intervenção urbana, aquela voltada para a revitalização de áreas deterioradas, e traz um relato de algumas experiências relevantes do gênero. Para tanto, apoia-se numa base teórica para conceituar e classificar os tipos de intervenção mais comuns, e apresenta dados sobre alguns casos bem sucedidos.
Nesta pesquisa, observa-se que, sobretudo que a partir dos anos de 1950, com o crescimento das cidades, parte dos espaços urbanos ficavam ociosos ou degradados. Para recuperação dessas áreas, foram adotados diversos procedimentos de projetos urbanos, a partir disto, este trabalho busca identificar algumas ações que possibilitaram a melhoria desses espaços.

\footnotetext{
1 Arquiteta, professora e pesquisadora da UEL. Mestre em Arquitetura e Urbanismo pela FAU/USP, doutora pela FAU/USP. E-mail: deniserj@uel.br. Coordenadora do Projeto.

2 Arquiteto, professor e pesquisador da UEL. Mestre em Desenvolvimento Urbano pela UFP, doutor em Estruturas Ambientais Urbanas pela FAU/USP. Colaborador.
} 


\section{As revitalizações urbanas}

A partir da segunda metade do Século XX, novos tipos de projetos urbanos ${ }^{1}$ passaram a ser realizados, adotando-se práticas urbanísticas que auxiliassem no renascimento e fortalecimento econômico, social e cultural de áreas decadentes ou abandonadas nas cidades, procurando dar-lhes nova vida.

De acordo com Hall (1998), o período de decadência econômica ocorrido nos anos de 1970 e 1980 em alguns países desenvolvidos, como Inglaterra e EUA, levou ao fechamento de grande número de indústrias manufatureiras, afetadas pelo aumento da concorrência e pela queda dos lucros, e fez desaparecer muitos empregos das regiões industriais. Como conseqüência, nas cidades várias áreas foram abandonadas - entre elas espaços privilegiados, como áreas industriais e portuárias - e tiveram que se reestruturar para abrigar novas atividades.

No centro das cidades, o declínio econômico se deu particularmente pela queda das atividades no varejo, devido à mudança nos hábitos de parte da população, que foi morar em bairros afastados e passou a fazer compras no comércio próximo de casa ou em shopping centers.

Para solucionar os problemas de abandono ou decadência de partes das cidades, surgiu um novo modelo de intervenção urbana, denominado revitalização urbana ${ }^{2}$, o qual deveria se apoiar em novos empreendimentos, criando incentivos e condições satisfatórias para a viabilidade dos projetos (JANUZZI, 2006).

Segundo Portas (1998), os projetos de revitalização urbana têm como objetivos a renovação e/ou ampliação de espaços coletivos com infra-estrutura e embelezamento; as transformações de conexões, redes e interfaces; a revitalização de atividades urbanas; a fundação de novas centralidades; e a instalação de parques temáticos e de sistemas ambientais. Em outras ocasiões, os projetos podem estar relacionados a decisões públicas setoriais (negociações institucionais), eventos únicos (candidaturas a convenções) e/ou catástrofes, iniciativas de investimentos privados (contratação de parcerias) e a programas integrados municipais (candidaturas e contratos).

O projeto pode estar ligado ainda a fatores como um programa de financiamento de reestruturação ou de implantação de infra-estrutura. Uma intervenção urbana bem estruturada pode ter impacto no crescimento sócio econômico da cidade ou de uma região.

Para a eficácia dos programas de revitalização, são utilizados agentes catalisadores de desenvolvimento, ou seja, aquelas que acelerem e favoreçam o movimento das ações, dando início ao processo. Alguns exemplos de agentes catalizadores: áreas de importância cívico-simbólica, conjuntos históricoarquitetônicos, áreas habitacionais, áreas comerciais e de serviços, shopping centers, conjuntos culturais, áreas de lazer e compras, novas áreas de pedestres, centros de convenções e aquários, mercados etc.

Os projetos propriamente ditos devem trazer uma lista de objetivos amplos e a descrição dos problemas de infra-estrutura, e devem levar em conta a malha urbana existente, discriminando as edificações a serem preservadas. Vários tipos de atividades são inseridas nos projetos, como lazer, comércio, serviços, turismo, cultura, habitação, etc. O objetivo da intervenção deve ser claro, considerando o conjunto de ambientes que a cidade possui, determinando o tipo de intervenção, a teoria urbana e a política urbana no processo de planejamento, conectando as relações entre os ambientes.

Aplicado em importantes cidades, esse modelo de revitalização destacou-se a partir de algumas experiências bem sucedidas.

1 De acordo com Manuel de Sola-Morales I Rubió (1997), no livro Las Formas de Crecimiento Urbano, "o projeto urbanístico é um projeto para dar forma a um processo físico, arquitetônico e de engenharia, que combine solo, edificação e infra-estrutura".

2 Carta de Lisboa (1995). Revitalização Urbana - "Engloba operações destinadas a relançar a vida econômica e social de uma parte da cidade em decadência. Esta noção, próxima de reabilitação urbana, aplica-se a todas as zonas da cidade, sem ou com identidade e características marcadas". 


\section{Algumas experiências no exterior: Baltimore,} Barcelona e Bilbao

Nos Estados Unidos, a revitalização do porto de Baltimore foi um exemplo de revitalização e parceria com a iniciativa privada que levou à valorização de espaços coletivos. No final da década de 50, quando a cidade começou a sofrer com o abandono das áreas centrais e o declínio do porto, foi elaborado, pela iniciativa privada, um plano para recuperação da área do porto, com a conservação de alguns edifícios de valor histórico e a proposta de uma combinação de usos. O projeto previa habitação, comércio, serviços, lazer e turismo cultural, feira-mercado, salas de convenções, aquário e estacionamento público no subsolo (Figura 1). O plano se estendeu para a área de Inner.

Harbor (porto interior), que se tornou um ponto de atração turística (DEL RIO, 1990, 1999).

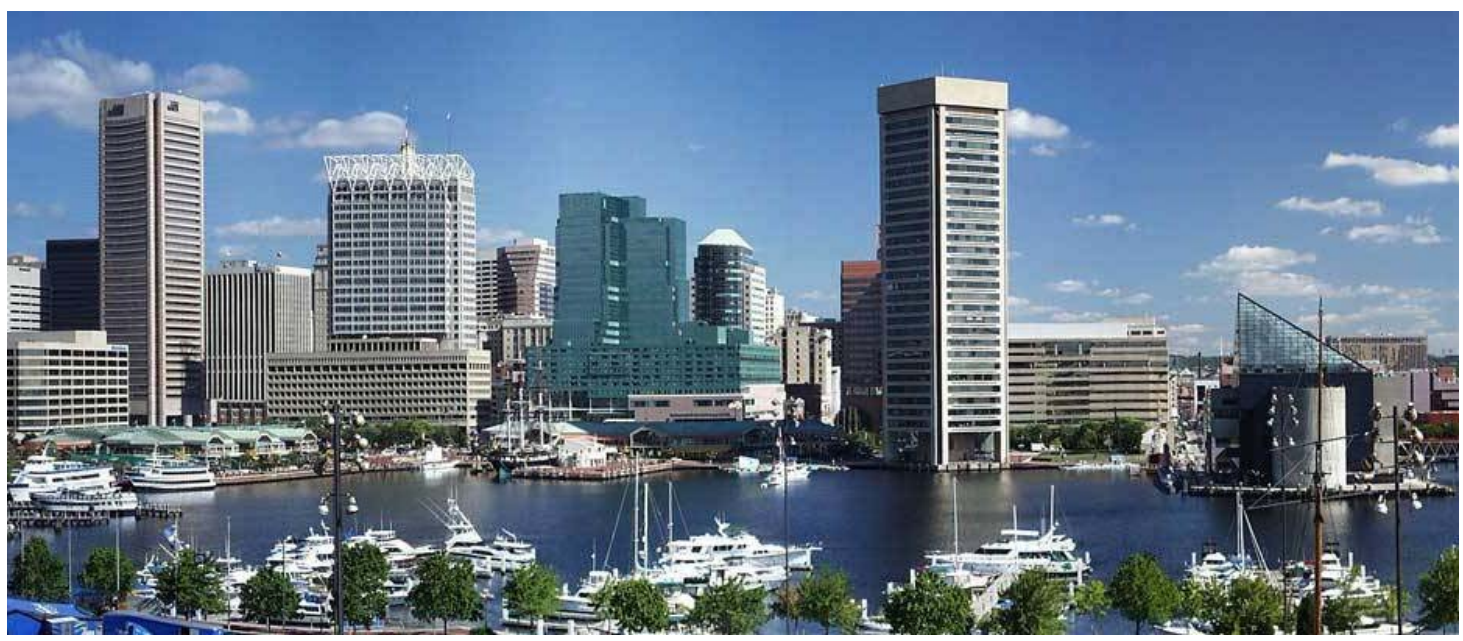

Figura 1. Inner Harbor (porto interior), em Baltimore.

Fonte: www.baltimore.to/baltimore_panorama.html. Acesso em: 08 jun. 2007.

Na Espanha, a revitalização de Barcelona esteve relacionada à realização dos Jogos Olímpicos de 1992. Foi montada uma estrutura para a realização dos Jogos Olímpicos, com equipamentos para esportes náuticos, buscando a integração com a cidade ao término dos Jogos (Figura 2). O governo espanhol desenvolveu um programa de recuperação da cidade, com mais espaços para lazer, mais atrativos turísticos e melhorias na circulação. (SALES, 1999).

A cidade de Bilbao sofreu com a decadência econômica, ambiental e com os fluxos migratórios. Em função disso, nos anos 70, foi preparado um plano para a recuperação de áreas deterioradas. O plano previa o saneamento do rio Nervión e de toda área metropolitana de Bilbao. A finalidade era transformar a cidade num centro financeiro e de serviços, industrial e comercial de referência. Nesse contexto, deu-se a construção do Museu Guggenheim Bilbao, desenhado por Frank O. Gehry, que abriu as portas em 1997; do novo terminal no aeroporto, projetado por Santiago Calatrava; de um novo terminal ferroviário metropolitano, desenhado por Norman Foster, inaugurado em 1995; de uma estação combinada de ônibus e trens desenhada por James Stirling e Michael Wilford; do centro empresarial de Abandoibarra; e foi feita a recuperação para o uso urbano da área antiga do porto, com a previsão de ampliação do porto atual. (site www.bm30.es/plan/pri-es.htm) (Figura 3). Para Powel (2000), o renascimento de Bilbao não se apoiou essencialmente na criação de monumentos isolados, mas em uma estratégia de desenvolvimento integrado na qual se salientava a importância da infra-estrutura no processo de regeneração. 


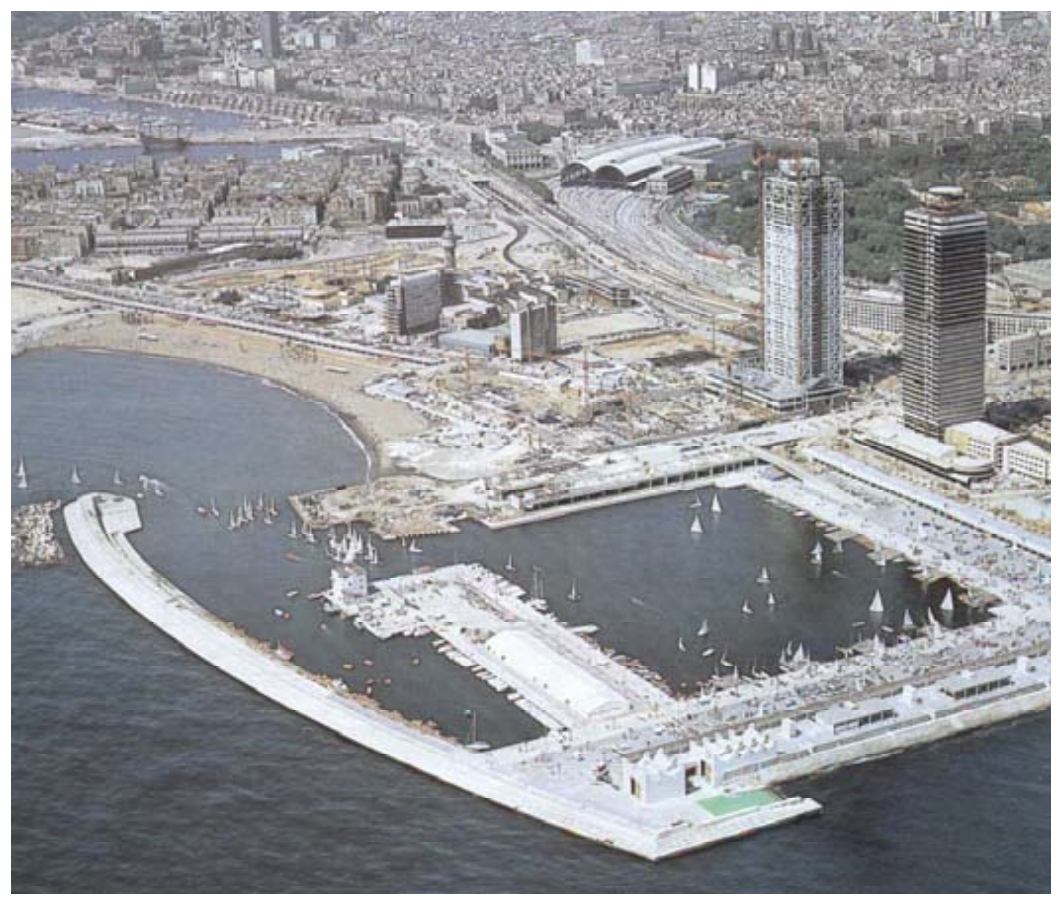

Figura 2. Vila Olímpica, Barcelona.

Fonte: Villá, 1992, p. 75.

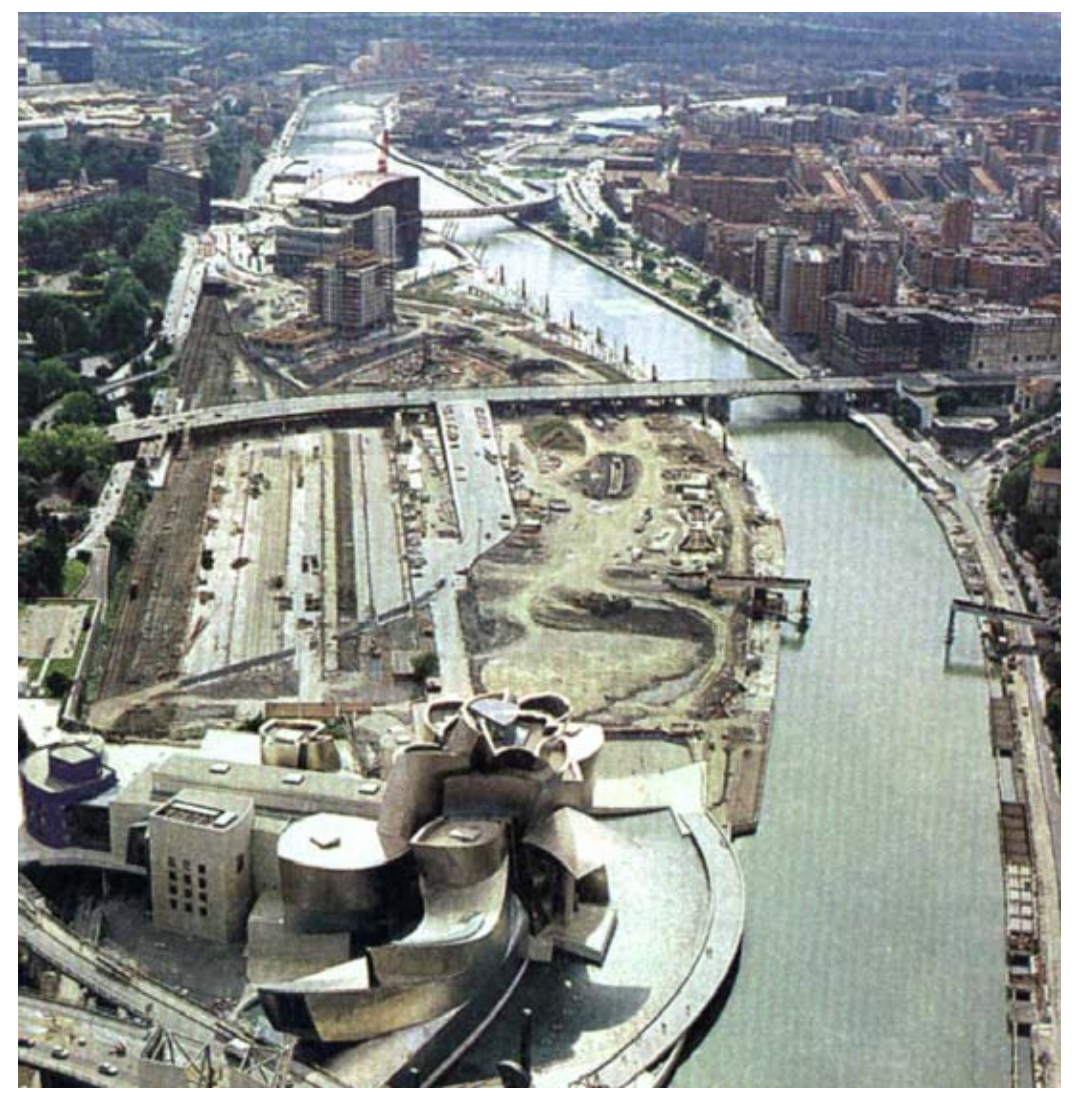

Figura 3. Vista aérea de Bilbao.

Fonte: Raul Juste Loures, fev. 2003. 


\section{Experiências no Brasil: Curitiba, São Paulo e Rio de Janeiro}

No Brasil, desde a década de 60 vêm sendo desenvolvidas experiências de revitalização urbana. Uma das primeiras iniciativas, em 1965, surgiu com o Plano Diretor de Curitiba, o SERETE, que criou diretrizes de planejamento para o crescimento da cidade. Entre as diretrizes, o plano previa o crescimento linear de um centro servido por vias tangenciais de circulação rápida, hierarquia de vias, desenvolvimento preferencial da cidade no sentido nordeste-sudoeste, conforme as tendências históricas e espontâneas, policentrismo, adensamento, extensão e adequação de áreas verdes, caracterização de áreas de domínio de pedestres e criação de uma paisagem própria, segundo o Instituto de Pesquisa e Planejamento Urbano de Curitiba (IPPUC, 2005).
Foi a partir dessas diretrizes que se criou o Calçadão da Rua XV de Novembro, em conjunto com um programa de recuperação e preservação da área histórica tradicional. Nesse programa, delineouse o perfil da paisagem curitibana com novas regras de zoneamento, ampliou-se a quantidade de áreas verdes, com a criação de novos parques, e realizouse uma reestruturação do sistema viário (Figura 4).

O projeto do Calçadão de Curitiba proporcionou um belo contraste entre a rua de pedestres e as edificações que após a implantação do Calçadão passaram por um processo de restauro. A criação do Calçadão da Rua das Flores fez da rua um importante ponto comercial e de encontro de pessoas, demonstrando ser um empreendimento de sucesso imediato tanto em público como em consumo. $\mathrm{O}$ exemplo de Curitiba foi amplamente divulgado e se reproduziu em várias cidades do Brasil.

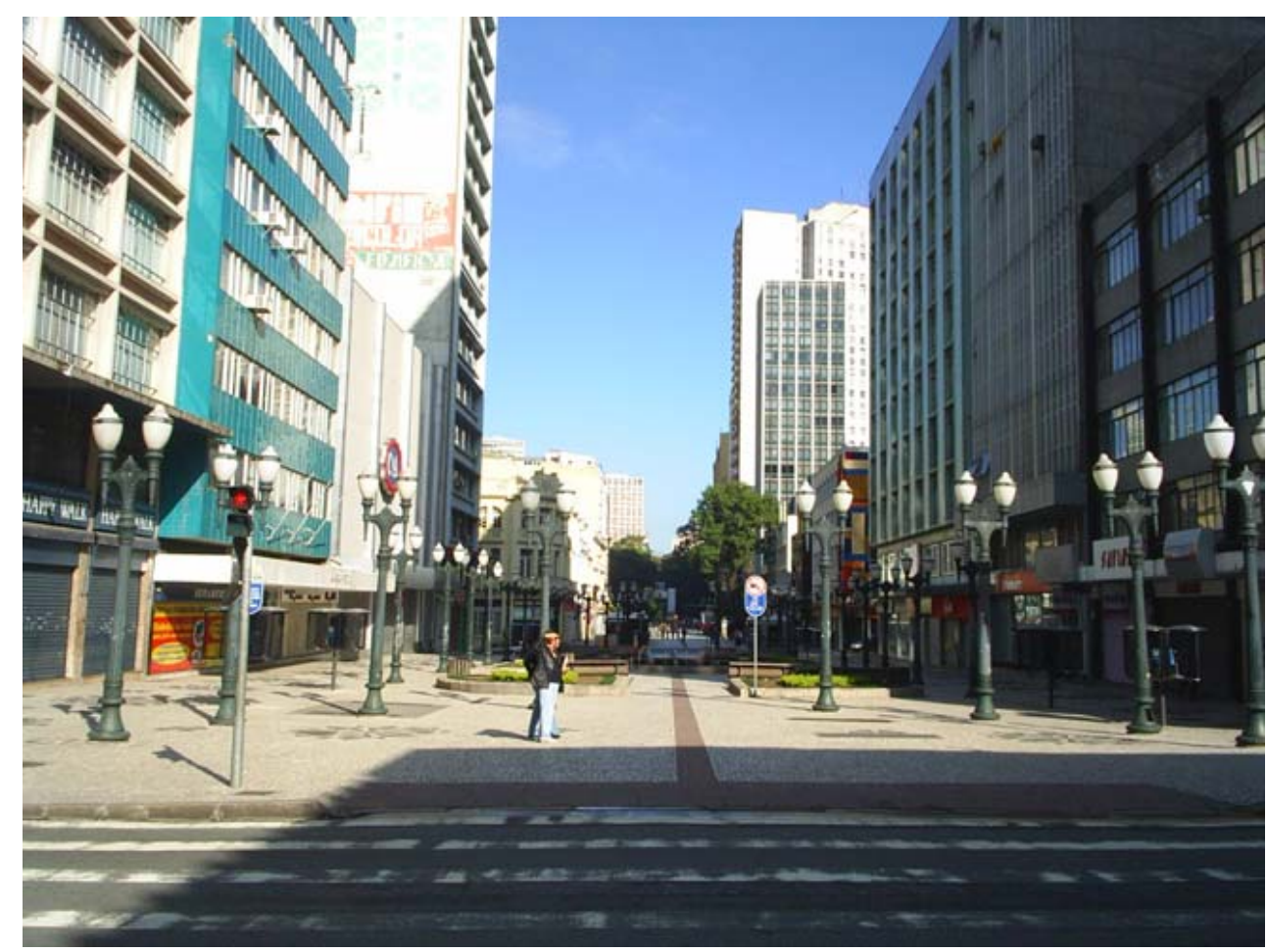

Figura 4. Calçadão da Rua XV de Novembro em Curitiba.

Fonte: Foto do Autor, 2005. 
No Rio de Janeiro, foi realizado um projeto de intervenção procurando revitalizar a área histórica e conciliar o crescimento da cidade com os espaços existentes, o projeto Corredor Cultural. De acordo com SIMÕES JÚNIOR (1994), a proposta abrangia o bairro da Lapa, incluindo o cais da Glória, o Campo de Santana, a Cinelândia, Carioca, Uruguaiana, Largo de São Francisco, Praça Tiradentes e uma parte da Praça XV (Figura 5). A intervenção tinha diferentes enfoques para cada região, entre eles a preservação do meio ambiente e a reconstituição e renovação urbana.

Conforme Vaz e Silveira (2006), o projeto Corredor Cultural teve como objetivo a preservação da arquitetura, do ambiente cultural e o incentivo à atividade comercial e cultural. Em conseqüência disso, a área central teve a manutenção e preservação do patrimônio edificado e a implantação de equipamentos culturais e de lazer, mas um aspecto desfavorável foi a expulsão de moradores do local.

Em São Paulo, nas últimas décadas foram realizados diversos projetos de revitalização. O do Vale do Anhangabaú, de autoria de Jorge Wilheim e Rosa Kliass, iniciado em 1981, foi um deles. O local passava por mudanças no sistema viário, estava decadente e precisava ser adequado às novas necessidades da área central da cidade, conforme Wilheim, Kliass e Kfouri (1992, p.32-41). Conforme Simões Júnior (1994), o projeto propôs a transformação do local numa grande praça, com espaços de lazer, resgatando sua função original de boulevard do início do Século XX (Figura 6). Assim, o Anhangabaú recuperou sua importância para a cidade, como praça com áreas verdes. No local existem bancos, floreiras, espelho d' água, sanitários, um mirante e um palco.
Esse foi um projeto integrador do centro histórico conectando marcos simbólicos consideráveis como: Parque D. Pedro II, o Viaduto do Chá e o de Santa Ifigênia, servindo de cartão postal da cidade, recuperando a área (FRÚGOLI JÚNIOR, 2000). A revitalização do Vale do Anhangabaú foi um dos projetos relevantes para a cidade de São Paulo, um projeto de pequena dimensão pelo tamanho da cidade a qual necessita de diversas ações de revitalização. Outros projetos foram criados e retomados em São Paulo, com a política de restauração de edifícios públicos, a restauração da Estação Júlio Prestes e a intervenção na Praça do Patriarca. Também surgiu um importante movimento organizado da sociedade civil, denominado Viva o Centro, o qual tem debatido os problemas do centro de São Paulo, em conjunto com a municipalidade buscando soluções para a melhoria da cidade.

\section{Considerações finais}

Pudemos verificar que existem diferentes tipos de intervenções urbanas, as quais apresentaram novos tipos de produção do espaço urbano, com uma diversidade de resultados. Em relação a experiências internacionais, a revitalização de Baltimore esteve relacionada a revitalização da área central e portuária com a preservação edifícios de valor histórico, que resultou na valorização dos espaços coletivos. A revitalização de Barcelona teve como enfoque a recuperação de áreas deterioradas, a reordenação da cidade com melhorias na circulação, aumento dos espaços para lazer e dos atrativos turísticos. Em Bilbao, a revitalização esteve ligada a recuperação ambiental, econômica e no controle dos fluxos migratórios de toda a área metropolitana, que resultou na construção de diversas edificações com idealizadas por arquitetos com fama internacional. 


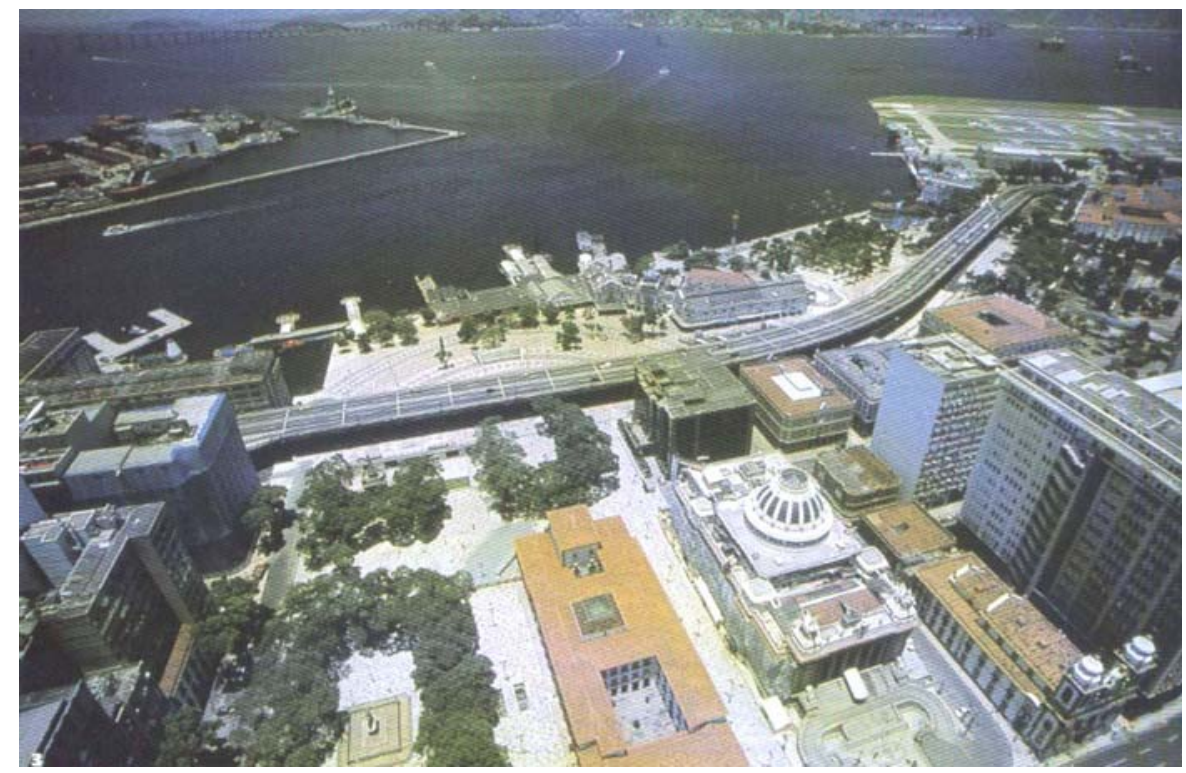

Figura 5. Praça XV, Rio de Janeiro.

Fonte: Waisman, 1998.

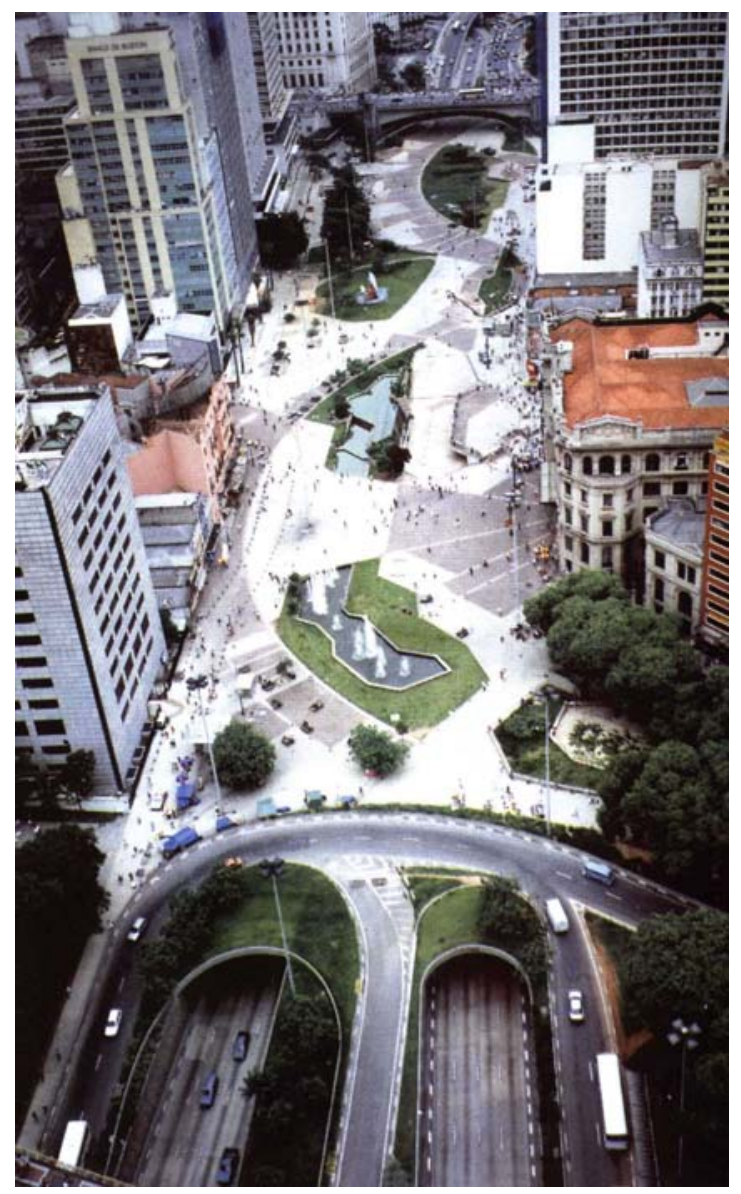

Figura 6. Vale do Anhangabaú, São Paulo.

Fonte: Macedo e Robba, 2002. 
Em relaçãoàs experiências nacionais, em Curitiba a revitalização partiu do plano diretor da década de 1960, quando reorganizaram o sistema viário da cidade, criaram a rua das Flores e diversos parques na cidade, melhorando a qualidade de vida da cidade. No Rio de Janeiro, o projeto Corredor Cultural procurou revitalizar a área histórica preservando a arquitetura, implantando equipamentos de cultura e lazer, conciliando o crescimento da cidade com os espaços existentes. Em São Paulo, o projeto de revitalização do Vale do Anhangabaú, serviu para recuperar o local, integrar o centro histórico, conectar os marcos simbólicos da cidade, ordenar o sistema viário e criar áreas de lazer, melhorando a imagem do lugar.

A revitalização urbana traduz uma nova postura de intervenção, que procura dar vitalidade às áreas através de um conjunto de ações, levando em consideração questões econômicas, sociais, funcionais e ambientais. O modelo de intervenção adotado procura dar uma nova vida às áreas das cidades através de um conjunto de ações que considera a situação do espaço existente e as relações humanas e econômicas que os envolvem.

Estudos mostram que, nas revitalizações, houve um planejamento detalhado, consideração com o ambiente existente, respeito ao entorno, estudos de ocupação para uso misto, criação de agentes catalizadores e de uma boa imagem, gestão contínua e participação de várias esferas. É importante salientar que não existe uma regra geral para a realização de uma intervenção: cada situação exige um estudo apropriado, tendo em vista os fins que se pretende atingir.

\section{Referências}

DEL RIO, V. Voltando às origens: a revitalização de áreas portuárias nos centros urbanos. Disponível em: <www. vitruvius.com.br>. Acesso em: 18 maio 1999.

Introdução ao desenho urbano no processo de planejamento. São Paulo: Pini, 1990.
FRÚGOLI JÚNIOR, H. Centralidade em São Paulo: trajetórias, conflitos e negociações na metrópole. São Paulo: Cortez, 2000.

HALL, P. Cidades do Amanhã: uma história do planejamento e do projeto urbano no século XX. São Paulo: Perspectiva, 1998.

INSTITUTO DE PESQUISA E PLANEJAMENTO URBANO DE CURITIBA - IPPUC. Plano diretor. Curitiba: IPUUC, 2005.

JANUZZI, D. C. R. Calçadões: a revitalização urbana e a valorização das estruturas comerciais em áreas centrais. 2006. 2006. Tese (Mestrado em Arquitetura e Urbanismo) - Universidade de São Paulo, São Paulo.

MACEDO, S. S.; ROBBA, F. Praças brasileiras: public squares in Brazil. São Paulo: Edusp, 2002.

MOURA, E. Operação complexa. $A U$ : Arquitetura e Urbanismo, São Paulo, v. 1, n. 42, p. 38-39, jun./jul., 1992.

PORTAS, N. Interpretazioni del progetto urbano: l'emergenza del progetto urbano. Revista Urbanística, Roma, v. 110, n.1, p. 51-60, giugno 1998.

POWEL, K. La transformacion de lam ciudad: 25 proyectos internacionales de arquitectura urbana a principios do século XXI. Barcelona: Blume, 2000.

SALES, M. M. L. Projeto urbano: opção metodológica e algumas práticas. 1999. Dissertação (Mestrado em Arquitetura e Urbanismo) - Universidade de São Paulo, São Paulo.

SIMÕES JÚNIOR, J. G. Revitalização de centros urbanos. São Paulo: Pólis, 1994.

VARGAS, H. C.; CASTILHO, A. L. A Lapa boêmia na cidade do Rio de Janeiro: um processo de regeneração cultural? Projetos, intervenções e dinâmica do lugar. In: VAZ, L. F.; SILVEIRA, C. B. Intervenções em centros urbanos:objetivos, estratégias e resultados. Barueri: Manole, 2006. p.67-99.

VILLÁ, J. Barcelona/Anos 90: saudade das utopias. $A U$ : Arquitetura e Urbanismo, São Paulo, v.1, n. 41, p.69-75, abr./maio 1992.

WILHEIM, J.; KLIASS, R. G.; KFOURI, J. J. Vale do Anhangabaú, SP: Nova feição do centro. $A U$ : Arquitetura e Urbanismo, São Paulo, v. 8, n. 42, p.32-41, jun./jul. 1992. 